demonstrated the feasibility and utility of including such questions in general health surveys, providing a useful vehicle for monitoring sexual risk behaviour more frequently than is possible with decennial Natsal surveys.

\section{P196 SERVICE EVALUATION: SEXUAL HEALTH PROMOTION A "MISSED" OPPORTUNITY FOR YOUNG PEOPLE?}

doi:10.1136/sextrans-2012-050601c.196

${ }^{1} \mathrm{C}$ Lutterodt, ${ }^{2} \mathrm{~L}$ Wong-Taylor, ${ }^{2} \mathrm{~B}$ White, ${ }^{2} \mathrm{G}$ Lewis. ${ }^{1} 75$ London road, London, UK; ${ }^{2}$ University College Hospital, London, UK

Background There is currently no widely accepted guidelines regarding sexual health promotion for paediatric staff. Consequently, valuable opportunities to provide much needed education are unfortunately being "missed". Young people (YP) in hospital have an ideal opportunity to discuss sexual health in confidence with healthcare workers.

Objectives The objective of this service evaluation was to assess the role of healthcare professionals and their views on providing sexual health education to adolescents on the wards. Understanding perceived views and identifying barriers and leavers is crucial in exploring some of the reasons behind why potentially ideal situations to provide sexual health information are currently being "missed".

Methods Questionnaires were completed by paediatric staff members. The responses were anonymised and data were collected from mid-October 2011 until the end January 2012.

Results The overall response rate was $81 \%$. The skills paediatric staff felt they possessed were: advising how to protect against pregnancy (91\%), STDs (90\%), prescribing contraception (61\%), screening for psychosocial issues (26\%), testing (34\%) and treating STDs (40\%). Almost $20 \%$ did not know about local sexual health centres. Furthermore, GPs were cited as the most appropriate healthcare professional to provide sexual health information.

Conclusion There appears to be a role for sexual health education within secondary care. We suggest that opportunistic health promotion should be considered by paediatric staff when dealing with YPs. Clearer guidance would minimise the number of "missed" opportunities and additional information sources (eg, leaflets) for patients and staff would enhance the provision of health promotion.

\section{P197 \\ YOUNG ASIAN SEXUAL HEALTH: WHAT CAN YOUNG INDIAN, PAKISTANI AND BANGLADESHI PEOPLE TELL US ABOUT THEIR BELIEFS, ATTITUDES AND BEHAVIOURS REGARDING SEXUAL HEALTH AND SEX AND RELATIONSHIPS EDUCATION?}

doi:10.1136/sextrans-2012-050601c.197

J Reynolds-Wright, ${ }^{*}$ N Alice, M Michelle, H Kanabar. University of Sheffield, Sheffield, UK

Introduction Young people's sexual health in the UK has been a concern for public health policy and, despite falling teenage pregnancy rates, sexually transmitted infections (STIs) among young people have shown an increase. The numbers of Asian teenagers engaging in sexual intercourse is reportedly lower than their Black counterparts, however, there is some evidence that Asian young people are more likely to report "regretful intercourse", "unequal willingness" and higher rates of anal intercourse, and so are still at risk of STIs through their behaviour.

Methods 16-25-year-old South Asian people were recruited from schools, universities and community organisations to participate in focus group (FG) or individual interviews. The Topic guide was developed following a literature review, steering group discussions and pilot FG. Following each FG or interview, emergent themes were explored in subsequent discussions. Ethical Permission was granted by NHS South Yorkshire Research Ethics Committee.

Results NVivo 8 software was used to code, organise and support thematic analysis. A total of five FGs and six interviews have been completed and analysis indicates five over-arching themes: (1). Formal sex and relationships education (SRE) (2). Informal SRE (3). Relationships (4). Barriers to access of SRE and sexual health services (5). Future development

Conclusion South Asian young people have distinct health education needs that are underpinned and informed by their ethnic, religious and cultural background. In order to deliver the best level of care to this group, awareness of these needs is essential. 